\title{
Propriedades PSICOMÉTRICAS DA ESCALA DE Sensibilidade à Ansiedade Revisada
}

Maria Rachel Pessanha Gimenes Escocard

O presente estudo avaliou as propriedades psicométricas e a estrutura fatorial da Escala de Sensibilidade à Ansiedade Revisada (ESA-R) em 585 pacientes com Transtorno de Ansiedade. Os resultados indicaram que essa versão da escala possui boa consistência interna e boa correlação de coeficiente item-total. A análise fatorial exploratória sugeriu que os fatores da ESA-R, quando comparados com os diferentes grupos de Transtorno de Ansiedade, indicam que pacientes com Transtorno do Pânico apresentam um escore significativamente mais elevado em quase todas as dimensōes da escala.

\section{BANCA:}

Jesus Landeira Fernandez (Orientador)

Jorge Ferreira da Silva

Monah Winograd

Data de defesa: 10/08/2007 